\title{
Hepatobiliary Tumors: Update on Diagnosis and Management
}

\author{
Ghassan Kabbach ${ }^{1}$, Hussein A Assi ${ }^{1}$, George Bolotin ${ }^{2}$, Michael Schuster ${ }^{2}$, Hwa Jeong Lee ${ }^{3}$ \\ and Micheal Tadros*4 \\ ${ }^{1}$ Department of internal medicine, Albany medical center, Albany, NY, USA; ${ }^{2}$ Department of radiology, Albany medical center, \\ Albany, NY, USA; ${ }^{3}$ Department of pathology, Albany medical center, Albany, NY, USA; ${ }^{4}$ Department of internal medicine, \\ Division of gastroenterology, Albany medical center, Albany, NY, USA
}

\begin{abstract}
Tumors of the liver and biliary tree, mainly hepatocellular carcinoma and cholangiocarcinoma, are the second leading cause of cancer related death worldwide and the sixth leading cause of cancer related death among men in developed countries. Recent developments in biomarkers and imaging modalities have enhanced early detection and accurate diagnosis of these highly fatal malignancies. These advances include serological testing, micro-ribonucleic acids, fluorescence in situ hybridization, contrast-enhanced ultrasound, and hepatobiliary-phase magnetic resonance imaging. In addition, there have been major developments in the surgical and nonsurgical management of these tumors, including expansion of the liver transplantation criteria, new locoregional treatments, and molecularly targeted therapies. In this article, we review various types of hepatobiliary tumors and discuss new developments in their diagnosis and management.

(c) 2015 The Second Affiliated Hospital of Chongqing Medical University. Published by XIA \& HE Publishing Ltd. All rights reserved.
\end{abstract}

\section{Introduction}

The yearly worldwide burden of hepatobiliary malignancy is estimated to be 782,500 new liver cancer cases and 745,500

Keywords: Hepatobiliary tumors; Hepatocellular carcinoma; Cholangiocarcinoma; Liver cancer; Diagnosis; Treatment; Management.

Abbreviations: AFP, $\alpha$-fetoprotein; AASLD, American Association for the Study of Liver Disease; APASL, Asian Pacific Association for the Study of the Liver; BCLC, Barcelona Clinic Liver Cancer; CCA, cholangiocarcinoma; CEUS, contrast-enhanced ultrasound; CLIP, cancer of the liver Italian program; CUPI, Chinese University Prognostic Index; DCP, des- $\gamma$ carboxiprothrombin; DNA, deoxyribonucleic acid; EASL, European Association for Study of The Liver; EHE, epithelioid hemangioendothelioma; FISH, fluorescence in situ hybridization; FLC, fibrolamellar carcinoma; FLR, future liver remnant; FNA, fine-needle aspiration; FNH, focal nodular hyperplasia; GP73, golgi protein 73; GPC-3, glypican-3; HBV, hepatitis B virus; HCA hepatocellular adenoma; $\mathrm{HCC}$, hepatocellular carcinoma; HCV, hepatitis $\mathrm{C}$ virus; $\mathrm{HEH}$, hepatic epithelioid hemangioendothelioma; IV, intravenous; JSH, Japan Society of Hepatology; MDCT, multidetector CT; miRNA, micro-ribonucleic acid; MRI, magnetic resonance imaging; NAFLD, nonalcoholic fatty liver disease; NASH, nonalcoholic steatohepatitis; OC, oral contraceptive; OLT, orthotopic liver transplantation; PEI, percutaneous ethanol injection; PET, positron emission tomography; PVE, portal vein embolization; RFA, radiofrequency ablation; SPIO, superparamagnetic iron oxide; TACE, transcatheter chemoembolization; US, ultrasound; Y90, yttrium-90.

Received: 20 April 2015; Revised: 22 May 2015; Accepted: 26 May 2015

DOI: $10.14218 /$ JCTH.2015.00012.

*Correspondence to: Micheal Tadros, Department of Medicine, Division of Gastroenterology, Albany Medical Center, 47 New Scotland Avenue, MC 48, Albany, NY 12208, USA. Tel: +1-518-262-5276, Fax: +1-518-262-6470, E-mail: tradrosm1@ mail.amc.edu liver cancer related deaths, according to the Global Cancer Statistics of $2012 .{ }^{1}$ More than $80 \%$ of cases of hepatocellular carcinoma (HCC) occur in Asia and are linked to the hepatitis B virus (HBV) epidemic. ${ }^{2}$ Notable differences exist between Asian and Western regions in guidelines on surveillance, diagnosis, and management of hepatobiliary tumors, which reflect differences in the epidemiological and etiological factors underlying the disease as well as socioeconomic factors due to the large disease burden in Asia. The most common adult malignant liver tumors are HCC, metastases to the liver, fibrolamellar HCC, epithelioid hemangioendothelioma (EHE), and angiosarcoma. Benign liver tumors include focal nodular hyperplasia, hepatic adenomas, and hemangiomas. Biliary tract malignancies include cholangiocarcinoma (CCA), both intra- and extrahepatic, gallbladder cancer, and cancer of the ampulla of Vater. Benign biliary neoplasms include biliary cystadenoma, biliary hamartoma, and granular cell tumors. An outline for the different hepatobiliary tumors is shown in Fig. 1. The epidemiology, risk factors, surveillance, diagnostic strategies, and treatment guidelines will be discussed for the most common types of hepatobiliary tumors, with particular emphasis on the newest modalities, clinical trials, and, when applicable, controversies in different international guidelines.

HCC

\section{Introduction}

Worldwide, HCC is one of the most common cancers, with more than half a million new cases reported each year, and is considered the third leading cause of cancer related death. It is the fifth most common cause of cancer in men and the seventh in women. ${ }^{3}$ At least 20,000 new cases are diagnosed in the United States every year. ${ }^{4}$ Significant heterogeneity exists in the epidemiology of HCC, with the highest incidence found in eastern Asia and Sub-Saharan Africa. ${ }^{5}$ The incidence rates are generally two to three fold higher in men than in women. While the incidence of HCC has decreased in some Asian regions with traditionally high-incidence, the incidence is rising in North America due to the obesity epidemic and the increased risk for developing nonalcoholic fatty liver disease (NAFLD). ${ }^{6}$ Overall, 5 year survival from liver cancer diagnosis in the United States was $15 \%$ in 2002-2008. ${ }^{7}$

\section{Risk factors}

$\mathrm{HBV}$ infection is the most common risk factor for HCC, with more than $50 \%$ of all liver cancers attributed to $\mathrm{HBV}^{8}{ }^{8}$ In 
Kabbach G. et al: Hepatobiliary tumors

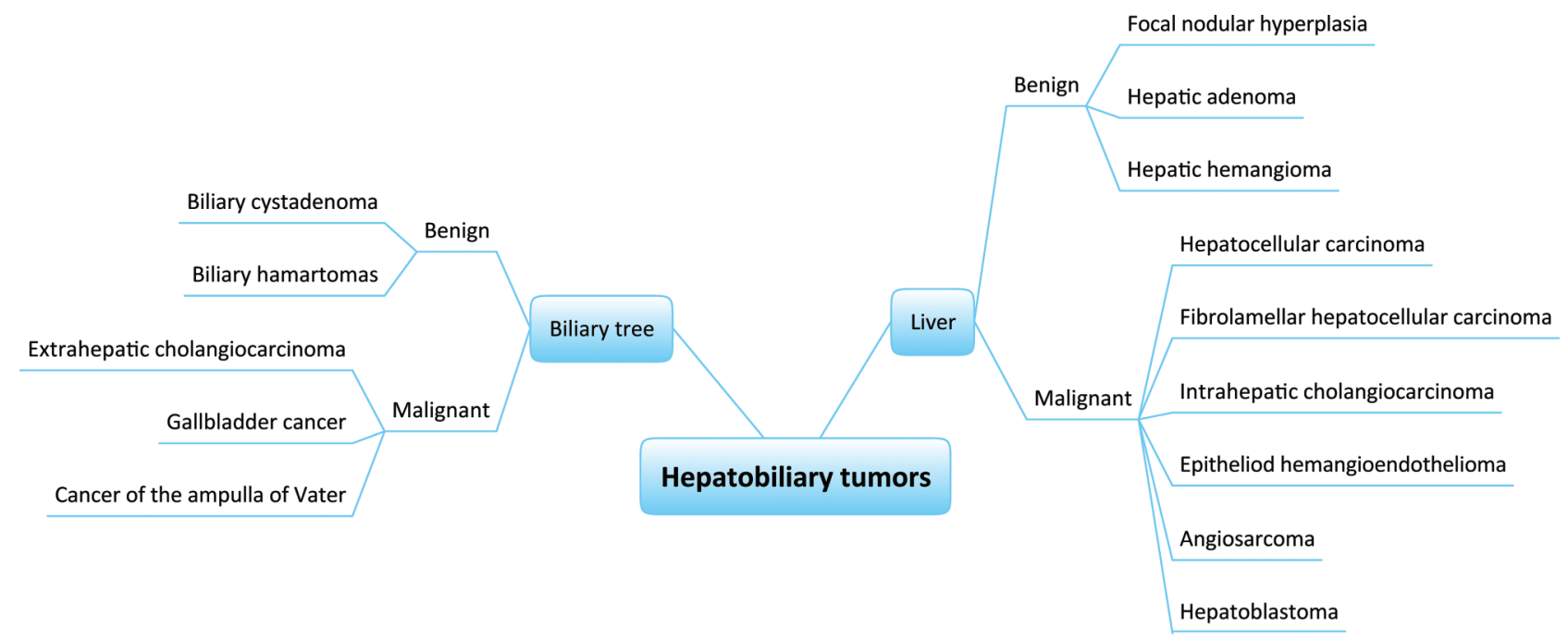

Fig. 1. List of malignant and benign hepatobiliary tumors.

North America, however, less than $10 \%$ of HCC cases are attributed to HBV, whereas $70 \%$ of cases in China and western and central Africa are attributed to HBV. ${ }^{5}$ Occult HBV infection is also associated with increased risk, since HBV integrates into human deoxyribonucleic acid (DNA). The relative risk of HCC is 100 times greater in HBV carriers compared to noncarriers, and this risk is further increased in those with HBV-associated cirrhosis. ${ }^{9}$ HBV-related HCC is preventable by vaccination, and antiviral treatment in chronic $\mathrm{HBV}$ may decrease the risk for HCC. ${ }^{10}$ Compared to HBV, hepatitis $\mathrm{C}$ virus (HCV)-related $\mathrm{HCC}$ almost always occurs in the presence of cirrhosis. The incidence of $\mathrm{HCC}$ in $\mathrm{HCV}$ associated cirrhosis is $3-5 \%$ per year, with a $20-30$ fold increase in risk relative to noninfected individuals. ${ }^{7,11}$ Unlike HBV, HCV does not integrate into the human genome.

Exposure to aflatoxin in southern China and Sub-Saharan Africa is a major risk factor for HCC, and HBV-carriers exposed to aflatoxin are at markedly increased risk for developing HCC. ${ }^{12}$ Efforts to control exposure to aflatoxin in endemic areas led to an appreciable reduction in liver cancer related mortality. Heavy alcohol use ( $>100 \mathrm{~g}$ per day), according to one large Korean cohort, also plays a role in the development of HCC. ${ }^{13}$ However, HCC typically develops in a background of alcoholic cirrhosis.

NAFLD/nonalcoholic steatohepatitis (NASH)-related HCC currently accounts for $10-24 \%$ of all HCC in Western countries. ${ }^{5}$ Both obesity (body mass index $>35 \mathrm{~kg} / \mathrm{m}^{2}$ ) and diabetes mellitus are associated with increased risk of HCC. ${ }^{6}$ Diabetes alone increased the risk of developing NAFLD, which included a spectrum from steatosis and NASH to liver fibrosis, cirrhosis, and ultimately HCC. Interestingly, metformin therapy in diabetic patients was shown to decrease the risk of developing HCC. ${ }^{14}$ While tobacco smoking was shown to increase the risk of HCC, though inconsistently, heavy coffee consumption was shown to be inversely related to the risk of $\mathrm{HCC}$, compared to light consumption and never drinkers. ${ }^{5}$

Other rare causes of HCC are well identified and include primary biliary cirrhosis, autoimmune hepatitis, hemochromatosis, Wilson's disease, alpha-1 antitrypsin deficiency, and glycogen storage diseases amongst others and typically occur in the presence of cirrhosis.

\section{Surveillance: role of ultrasound (US) and biomarkers}

The overall level of evidence in support of the use of surveillance for HCC in high risk patients, including patients with cirrhosis and HBV infection, is modest. Nevertheless, surveillance is endorsed by multiple societies, including the Asian Pacific Association for the Study of the Liver (APASL), ${ }^{15}$ the European Association for Study of The Liver (EASL), ${ }^{16}$ and the American Association for the Study of Liver Disease (AASLD). ${ }^{17}$ The best evidence comes from a large-scale, randomized controlled trial of surveillance of nearly 19,000 patients with $\mathrm{HBV}$ in China. ${ }^{18}$ Patients were randomly assigned to receive either surveillance with US and measurement of serum $\alpha$-fetoprotein (AFP) every 6 months or no surveillance. Survival of screened patients was $66 \%$ and $46 \%$ at 1 and 5 years, respectively, whereas it was only $31 \%$ and $0 \%$ at 1 and 5 years, respectively, in the unscreened group. Similarly, in a 16 year population-based study of Alaska natives with chronic hepatitis B who were screened with biannual AFP measurements, 5 year survival of screened patients was $42 \%$ and $0 \%$ in unscreened controls. ${ }^{19}$

US has a sensitivity of $78-90 \%$ and specificity of $93 \%$ in detecting HCC. ${ }^{15}$ In liver cirrhosis with regenerative nodules, however, the sensitivity for detecting early HCC ranged between $32 \%$ and $65 \% .{ }^{20}$ Similarly, AFP alone has a sensitivity ranging from $49 \%$ to $71 \%$ and specificity from 49 to $86 \%$ in detecting small HCC. Sensitivity drops to $25 \%$ for tumors smaller than $3 \mathrm{~cm} .{ }^{21}$ Nevertheless, a recent prospective study in cirrhotic patients showed that US, AFP, and combined US/ AFP had sensitivities of $44 \%, 66 \%$, and $91 \%$, and specificities of $92 \%, 91 \%$, and $83 \%$, respectively. ${ }^{20}$

The L3 isoform of AFP (AFP-L3) was shown to be more specific to HCC than benign liver disease and has utility to predict HCC at low AFP levels and in the absence of US findings. Similarly, des- $\gamma$ carboxiprothrombin (DCP), an abnormal prothrombin protein present in the sera of HCC patients, was shown to be specific to HCC and also to be a prognosticator. ${ }^{21}$ The combination of DCP and AFP resulted in an enhanced sensitivity of $90 \%$ in a large multicenter Chinese study of HBV-related HCC. ${ }^{22}$ AFP-L3 has also been combined with other new candidate proteins such as Golgi protein 73 
(GP73) with improved sensitivity (94\%). An interesting model by Johnson et al. combined age, gender, AFP, AFP-L3, and DCP (GALAD) to estimate the probability of developing HCC in a patient with chronic liver disease. Depending on the tumor stage, sensitivity was $86-94 \% .{ }^{23}$ Other novel and promising biomarkers include glypican-3 (GPC-3), interleukin-6, and osteopontin. ${ }^{21}$ Whether the studies performed in Asian populations, with a predominance of HBV infections, are applicable to Western populations with higher incidence of NASH-related $\mathrm{HCC}$ is debatable.

Another active area of research is the use of noncoding micro-ribonucleic acid (miRNA) in the diagnosis and prognostication of HCC. This methodology has generated much interest due to the stability of the molecule against degradation and the detectability of miRNAs in all types of human samples, such as blood and saliva. High quality analysis allowed for the generation of "microRNAome" for both healthy and diseased liver, including HCC. Subsequent analysis identified multiple candidate miRNAs, such as miR-25, miR-375, and let7f, that were able to identify HCC patients with a sensitivity of $98 \%$ and specificity of $99 \% .{ }^{24}$ Further studies also identified miR-21 and miR-122 as potential biomarkers ${ }^{25}$. Whether or not these models are applicable to nonHBV related HCC and are translatable to clinical practice remains to be elucidated.

Currently, the AASLD recommends surveillance with US every 6 months only in patients with hepatitis $C$ and expected HCC risk exceeding $1.5 \%$ per year and hepatitis $B$ patients with expected risk $>0.2 \%$ per year. ${ }^{17}$ The APASL, on the other hand, recommends the combined use of US and AFP every 6 months. $^{15}$ The Japan Society of Hepatology (JSH) recommends the use of US every 6 months in combination with measurements of all three serum markers: AFP, high-sensitivity AFP-L3, and DCP. In extremely high risk groups, the recommended surveillance frequency is every 3-4 months with optional addition of CT/MRI every 6-12 months. ${ }^{26}$ Some centers alternate US and magnetic resonance imaging (MRI), but this practice is not supported by current guidelines.

\section{Diagnosis}

The cornerstone for the diagnosis of HCC is typical radiological findings on contrast-enhanced computed tomography (CT) or MRI. Western guidelines stratify their diagnostic algorithm according to nodule size. In the AASLD guidelines, in a patient with cirrhosis or chronic hepatitis $B$, a nodule $>1 \mathrm{~cm}$ warrants 4-phase multidetector CT (MDCT) or dynamic MRI. ${ }^{17}$ Subsequently, intense arterial enhancement followed by portovenous or delayed-phase washout is sufficient to make the diagnosis of HCC. The sensitivity of imaging is dependent on the size of the nodule. Typical imaging features in a nodule of $1-2 \mathrm{~cm}$ have a sensitivity of $71 \%$ and a specificity and positive predictive value of nearly $100 \%$. This sensitivity is reduced to $33-45 \%$ for nodules $<1 \mathrm{~cm} .{ }^{15}$ On the other hand, Asian guidelines stratify their algorithm according to the presence of hypervascularity in the arterial phase on dynamic CT or MRI in a nodule detected by US. ${ }^{15}$ The subsequent presence of washout in the portal or venous phase is sufficient to diagnose HCC. Absence of washout, however, does not exclude HCC. MRI and CT scan features of $\mathrm{HCC}^{27}$ are summarized in Table 1 and Table 2, respectively.

Recently, new imaging modalities have been developed and are already in use as an integral part of the Japanese guidelines. ${ }^{26}$ Contrast-enhanced US (CEUS) utilizing second generation contrast agents, such as Sonazoid, has two phases: the vascular phase and Kupffer phase. ${ }^{28}$ Newer MRI contrast agents include the nongadolinium-based superparamagnetic iron oxide (SPIO) and gadolinium-based hepatobiliary agents, such as gadoxetic acid (Eovist), which has a delayed hepatobiliary uptake phase. ${ }^{29}$ When a nodule detected by CT or MRI shows typical arterial enhancement but fails to show washout in the portovenous phase or when an originally hypovascular nodule is detected, the utilization of SPIO-MRI or CEUS can be helpful. In these cases, lack of uptake in the Kupffer phase would be suggestive of HCC. ${ }^{15,29}$ Similarly, given the lack of proper biliary tracts in HCC, there would be little uptake of the hepatobiliary contrast Eovist. ${ }^{27}$ The appearance of HCC on MRI is shown in Fig. 2.

Table 1. List of systemic targeted therapies for advanced HCC as first and second line treatments

\begin{tabular}{|c|c|c|c|}
\hline & Trial & Design & Overall survival (months) \\
\hline \multirow[t]{7}{*}{ First line } & SHARP 51 & Sorafenib vs placebo & 10.7 vs $7.9, p<0.001$ \\
\hline & Asia-pacific & Sorafenib vs placebo & 6.5 vs $4.2, p=0.014$ \\
\hline & SUN 1170 & Sunitinib vs sorafenib & 7.9 vs $10.2, p=0.0029$ \\
\hline & BRISK-FL & Brivanib vs sorafenib & 9.5 vs $9.9, p=\mathrm{NS}$ \\
\hline & $01009593^{54}$ & Linifanib vs sorafenib & 9.1 vs $9.8, p=\mathrm{NS}$ \\
\hline & SEARCH ${ }^{53}$ & Erlotinib + sorafenib vs placebo + sorafenib & 9.5 vs $8.5, p=\mathrm{NS}$ \\
\hline & E7080 & Lenvatinib vs sorafenib & Phase III ongoing \\
\hline \multirow[t]{6}{*}{ Second line } & BRISK-PS & Brivanib vs placebo & 9.4 vs $8.2, p=\mathrm{NS}$ \\
\hline & EVOLVE-1 $1^{55}$ & Everolimus vs placebo & 7.6 vs $7.3, p=\mathrm{NS}$ \\
\hline & $\mathrm{REACH}$ & Ramucriumab vs placebo & 9.2 vs $7.6, p=\mathrm{NS}$ \\
\hline & RESOURCE & Regorafenib vs placebo & Phase III ongoing \\
\hline & METIV-HCC & Tivantinib vs placebo & Phase III ongoing \\
\hline & CELESTIAL & Cabozantinib vs placebo & Phase III ongoing \\
\hline
\end{tabular}

NS, not significant. Adapted from Kalyan et al, ${ }^{39}$ Qi et $a l,{ }^{56}$ and Chuma et al. ${ }^{49}$ 
Kabbach G. et al: Hepatobiliary tumors

Table 2. Summary of typical MRI findings in hepatobiliary tumors

\begin{tabular}{|c|c|c|c|c|}
\hline & Arterial phase & $\begin{array}{l}\text { Portal/venous or } \\
\text { delayed phase }\end{array}$ & T1-weighted MRI & T2-weighted MRI \\
\hline $\mathrm{HCC}$ & Early enhancement & $\begin{array}{l}\text { Portovenous: washout. } \\
\text { Delayed: rim-enhancing } \\
\text { capsule }\end{array}$ & Variable/hypointense & Hyperintense \\
\hline FLC & $\begin{array}{l}\text { Early heterogeneous } \\
\text { enhancement }\end{array}$ & $\begin{array}{l}\text { Homogeneous } \\
\text { enhancement }\end{array}$ & $\begin{array}{l}\text { Hypointense. Central } \\
\text { scar: hypointensity }\end{array}$ & $\begin{array}{l}\text { Hyperintense. Central } \\
\text { scar: hypointensity }\end{array}$ \\
\hline CCA & $\begin{array}{l}\text { Early peripheral } \\
\text { enhancement }\end{array}$ & $\begin{array}{l}\text { Delayed central } \\
\text { enhancement }\end{array}$ & Hypo or Isoattenuating & Variable hyperintensity \\
\hline FNH & Hypervascular & Isoattenuating & $\begin{array}{l}\text { Iso- to slightly } \\
\text { hypointense. Central } \\
\text { scar: hypointensity }\end{array}$ & $\begin{array}{l}\text { Iso- to hyperintense. } \\
\text { Central scar: } \\
\text { hyperintensity }\end{array}$ \\
\hline $\mathrm{HCA}$ & Rapid enhancement & $\begin{array}{l}\text { Isoattenuating but } \\
\text { occasional washout }\end{array}$ & Variable to hyperintense & $\begin{array}{l}\text { Slightly hyperintense } \\
\text { and heterogeneous }\end{array}$ \\
\hline Metastases & $\begin{array}{l}\text { Hypervascular, } \\
\text { multiple and } \\
\text { heterogeneous }\end{array}$ & $\begin{array}{l}\text { Less likely to be } \\
\text { isoattenuating }\end{array}$ & Variable hypointensity & Hyperintense \\
\hline
\end{tabular}

CCA, cholangiocarcinoma; FLC, fibrolamellar hepatocellular carcinoma; FNH, focal nodular hyperplasia; HCA, hepatocellular adenoma; HCC, hepatocellular carcinoma; MRI, magnetic resonance imaging.

The role of fine-needle aspiration (FNA) biopsy for the diagnosis of HCC is controversial but is a part of the AASLD guideline when a lesion suspicious for HCC does not show typical imaging features on multiphasic CT or MRI. The vastly heterogeneous histological features of HCC and controversies regarding the role of FNA have been extensively reviewed previously. ${ }^{30}$ Typical HCC histology is shown in Fig. 3A.

\section{Regenerative and dysplastic nodules}

Regenerative nodules show a vascular profile similar to normal liver parenchyma, whereas premalignant dysplastic nodules have a more variable vascular profile. Dysplastic nodules exhibit an opposite MRI pattern than HCC. They are hypointense on T2-weighted images and hyperintense on T1-weighted images. They also lack a capsule, while $90 \%$ of $\mathrm{HCC}>5 \mathrm{~cm}$ in Asian countries have a capsule. ${ }^{29}$
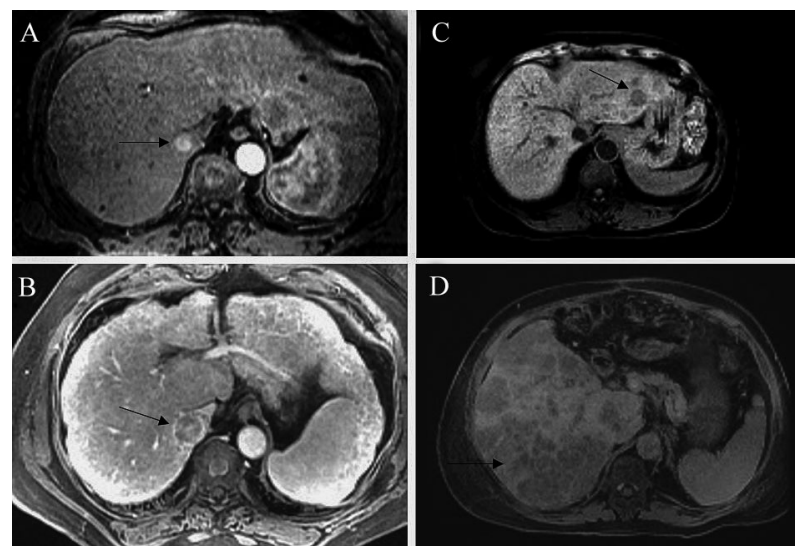

Fig. 2. Radiologic images of hepatocellular carcinoma (HCC). MRI images of HCC showing A, arterial enhancement; $B$, washout on portal venous phase with delayed capsular enhancement; $C$, Precontrast MRI showing hypointense lesion in another patient with HCC; D, MRI with 20 min delayed phase Eovist showing diffuse hypointense biopsy-proven HCC.

\section{Staging}

Multiple staging systems exist for HCC. Staging systems include the TNM staging system, Barcelona Clinic Liver Cancer staging system (BCLC), ${ }^{31}$ the Cancer of the Liver Italian Program (CLIP), the Okuda staging system, Japan Integrated Staging, and Chinese University Prognostic Index (CUPI). ${ }^{32,33}$ Treatment guidelines are now most commonly based on BCLC staging system. The BCLC identifies patients with early stage HCC who are potentially curable, intermediate and advanced stage patients to whom life-prolonging treatment can be offered, and end stage patients in whom treatment might cause more harm than benefit. The staging system is outlined in Fig. 2 .

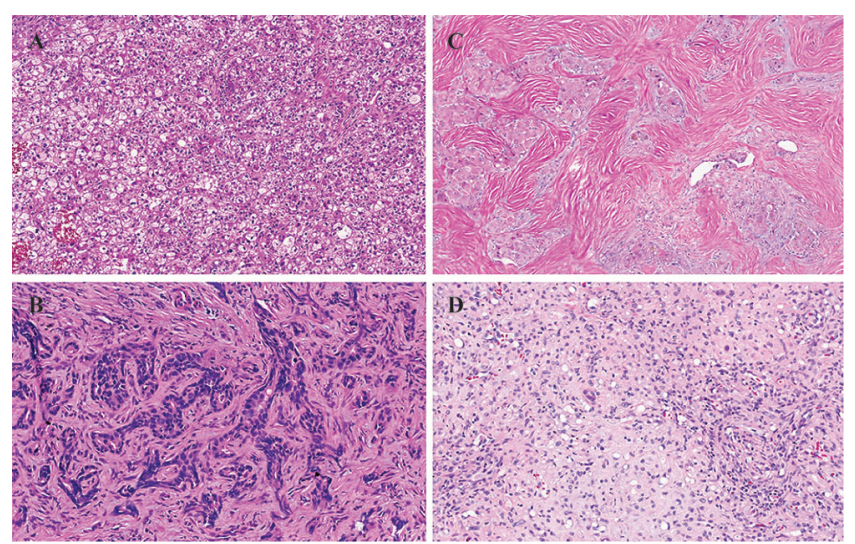

Fig. 3. Histopathology of malignant intrahepatic lesions. A, Hepatocellular carcinoma with moderate to marked cytologic atypia. The tumor is highly cellular, without intervening stroma $[\mathrm{H} \& \mathrm{E}, \times 100] ; \mathrm{B}$, Intrahepatic cholangiocarcinoma showing poorly formed neoplastic glands embedded within sclerotic stroma [H\&E, $\times$ 200]; C, Fibrolamellar type hepatocellular carcinoma showing abundant eosinophilic granular cytoplasm and prominent nucleoli within an area of dense sclerotic stroma $[\mathrm{H \& E}, \times 100] ; \mathrm{D}$, Epitheliod hemangioendothelioma demonstrating hyalinized stroma harboring entrapped blister cells with cytoplasmic lumen. Although the cells appear epithelioid, it is of endothelial origin [H\&E, $\times 200]$. 


\section{Treatment}

Treatment of HCC is based on the BCLC staging system. Potentially curative treatments, such as surgical resection or orthotopic liver transplantation (OLT), can be offered to patients in very early stages; and liver resection is the treatment of choice for those patients without underlying cirrhosis. Transplantation is very effective as it also addresses the underlying liver disease. Noncurative treatments include image-guided tumor radiofrequency ablation (RFA), transcatheter chemoembolization (TACE), and sorafenib (an oral tyrosine kinase inhibitor). Importantly, RFA may be curative in well-selected candidates. ${ }^{16}$ Current 5 year survival rate is $75 \%$ with curative treatments. ${ }^{34}$

Resection is the first-line treatment for patients with earlystage HCC and Child-Pugh class A. In Asia, indocyanine green retention rate at $15 \mathrm{~min}$ (ICG 15 ) is used to determine liver function. The presence of portal hypertension is a crucial prognostic indicator, ${ }^{35}$ and preoperative portal vein embolization (PVE) is often used to induce hypertrophy of the future liver remnant (FLR). PVE is indicated in patients with good hepatic reserve, measured as ICG 15 of $<20 \%$. The desired FLR volume is $20-25 \%$ typically and $40 \%$ in cirrhotic patients. ${ }^{36}$ Recurrence after resection, however, remains a problem and is attributed to de novo HCC if it occurs after 2 years and to true recurrence within 2 years. ${ }^{37}$ Interestingly, after resection, HBV patients show better survival and less recurrence compared to patients with $\mathrm{HCV}^{38}$ The Sorafenib as Adjuvant Treatment in the Prevention of Recurrence of Hepatocellular Carcinoma (STORM) trial demonstrated no improvement in recurrence-free survival with sorafenib, and currently, no adjuvant therapy has been shown to prevent recurrence. ${ }^{39}$ Repeat resection, OLT, or TACE can be offered for recurrent HCC. ${ }^{34}$

Transplantation is the ideal treatment choice for cirrhotic patients with early stage HCC, since it also allows treatment of the underlying condition. Five year survival after transplantation has dramatically improved and is equal to survival after resection, although there are no head-to-head trials comparing the two treatment options. The "Milan Criteria" was a landmark publication that defined a suitable transplant candidate - one with a solitary tumor $\leq 5 \mathrm{~cm}$ or $2-3$ nodules each $\leq 3 \mathrm{~cm} .{ }^{40}$ Recently the UCSF criteria (single nodule $<6.5 \mathrm{~cm}$ or $\leq 3$ nodules, the largest of which is $\leq 4.5 \mathrm{~cm}$ with a cumulative diameter $\leq 8 \mathrm{~cm}$ ) have demonstrated similar but less consistent results. ${ }^{41}$ Locoregional therapies, such as TACE and RFA, can be offered as a bridge to transplantation for "downstaging" and as a treatment of recurrence postOLT. ${ }^{34,37}$ On the other hand, perioperative use of sorafenib led to potentially worse outcomes in one recent meta-analysis. ${ }^{42}$

Thermal ablation (RFA or microwave) or ethanol-based chemical ablation is the treatment of choice for patients with a single small tumor who are otherwise not surgical candidates. Percutaneous ethanol injection (PEI) was more commonly performed for tumors $<2 \mathrm{~cm}$, but the superiority of RFA was established over PEI except in very small lesions. ${ }^{34}$ In contrast with the larger STORM trial, two recent studies showed that sorafenib combined with RFA significantly decreased recurrence rates and prolonged the survival time in HCC patients. ${ }^{43,44}$ Other ablative technologies, such as cryoablation and laser ablation, are still under investigation. ${ }^{16}$ Chemoembolization, or TACE, is the treatment of choice for patients with BCLC stage B HCC. Postembolization syndrome (fever, abdominal pain, ileus) is a well-known complication, and a total bilirubin greater than $3 \mathrm{mg} / \mathrm{mL}$ is a relative contraindication to TACE. ${ }^{34}$ Radioembolization via microspheres impregnated with yttrium-90 (Y90) has also been shown to be a promising and safe noncurative treatment for unresectable HCC. ${ }^{45}$

Multiple studies have looked at the combination of locoregional therapy, such as TACE with chemotherapeutic or targeted therapies. The SOCRATES trial ${ }^{46}$ initially showed promising effects of combination TACE + sorafenib for the treatment of unresectable HCC. More recent trials, such as the SPACE study, have shown that the administration of sorafenib with TACE + drug-eluting beads (DEB-TACE) has better time to progression (TTP) than DEB-TACE alone. ${ }^{47}$ On the other hand, combined TACE with brivanibl ${ }^{48}$ or orantinib (ORIENTAL trial) ${ }^{49}$ did not meet their primary end-points.

Systemic therapy with sorafenib is the first and only approved systemic treatment for patients with advanced HCC and Child's A cirrhosis. ${ }^{50,51}$ It prolonged survival from 7.9 to 10.7 months. ${ }^{51}$ The efficacy of sorafenib in Child's B cirrhosis has not yet been determined but appeared to be safe and well tolerated according to recent analysis of the GIDEON trial. ${ }^{52} \mathrm{~A}$ few trials have been undertaken to study new molecules either as first line treatments ${ }^{53,54}$ or as second-line agents, such as everolimus ${ }^{55}$ and have all thus far been negative. Some of those trials are summarized with their results in Table $1 .^{39,49,56}$ Please refer to the references cited for a more thorough discussion of this highly active area of research, which is beyond the scope of this article.

\section{Fibrolamellar HCC}

Fibrolamellar HCC (FLC) is a rare liver tumor that primarily affects younger individuals without underlying liver disease. The average age at presentation is 25 . Unlike HCC, there is no male predominance. In the United States, the age-adjusted incidence rate is estimated at 0.02 per 100,000 . No risk factors are yet known for FLC, but it has been reported in patients with ulcerative colitis, primary sclerosing cholangitis, and in pregnant patients. ${ }^{57-59}$

FLC presents as a large vascular tumor with prominent fibrosis (Fig. 3C). It can have central scarring with calcifications. Ultrasonographic features are nonspecific. While calcifications and a central scar are typically seen, central scarring is not pathognomonic for FLC. On CT scan, FLC appears welldefined and hypoattenuating on the unenhanced phase. It displays marked enhancement after intravenous (IV) contrast administration, with marked variability in attenuation on the portal venous and delayed phases. Contrast enhancement of the central scar is also variable. ${ }^{60}$ MRI features of FLC $^{60}$ are summarized in Table 2.

FLC typically does not present with elevated AFP levels, but patients can have slightly elevated aspartate and alanine aminotransferases (AST and ALT), high serum vitamin B12 binding capacity, and elevated neurotensin. However, the role of these molecules in the screening or diagnosis of FLC remains unestablished. ${ }^{57}$ A DNAJB1-PRKACA fusion transcript has recently been found to be $92 \%$ sensitive and $100 \%$ specific for the diagnosis of FLC. ${ }^{61}$

Evidence on treatment and prognosis of FLC is limited. Recently, Mavros et al. showed that 5 year survival for patients undergoing any treatment for FLC was 44\%, which is significantly better than typical 5 year survival figures of HCC. ${ }^{57}$ Chemotherapy has been used with limited success and includes fluorouracil with interferon- $\alpha$ and gemcitabine with oxaliplatin. ${ }^{62}$ Sorafenib has not been studied for the treatment of FLC. 


\section{EHE}

Hepatic EHE (HEH) is a rare neoplasm originating from the vascular endothelium of the liver, with its typical appearance shown in Fig. 3D. It has a 3:2 adult female predominance and has intermediate malignant potential. ${ }^{63,64}$ In a review of 402 $\mathrm{HEH}$ cases, usual MRI findings were a hypointense peripheral lesion with capsular retraction on T1-weighted images and with variable high intensity on T2-weighted images with a peripheral dark rim. It has variable enhancement on contrast MRI. ${ }^{65}$

Liver resection and transplantation provide the best outcome, with 5 year survival of $75 \%$ and $54 \%$, respectively. There is no consensus on optimal nonsurgical treatment for $\mathrm{HEH}$. Evidence is limited, but some of the chemotherapeutic agents used with varying response include interferon alfa-2a, bevacizumab, ranibizumab, pegaptanib, sunitinib, sorafenib, and thalidomide. ${ }^{65-67}$

\section{Benign liver tumors}

Benign liver tumors are common and can be divided into cystic and solid lesions. Cystic lesions are the most common and are easier to identify on imaging. Solid liver masses, however, represent a diagnostic challenge when discovered incidentally or during surveillance or staging for another primary malignancy. The three common benign solid hepatic tumors are hepatocellular adenoma (HCA), focal nodular hyperplasia (FNH), and hepatic hemangioma.

Hepatic hemangiomas are the most common noncystic benign liver tumor with an incidence of up to $20 \%{ }^{68}$ It is comprised of blood-filled vascular channels lined by a simple endothelial layer. The diagnosis of a hemangioma is usually clearly established by US. Three classical histologic subtypes have been identified: cavernous hemangioma, capillary hemangioma, and sclerosing hemangioma. Cavernous hemangiomas are the most common. The typical imaging characteristics of hemangiomas are provided in Table $4^{68,69}$ and shown in Fig. 4.
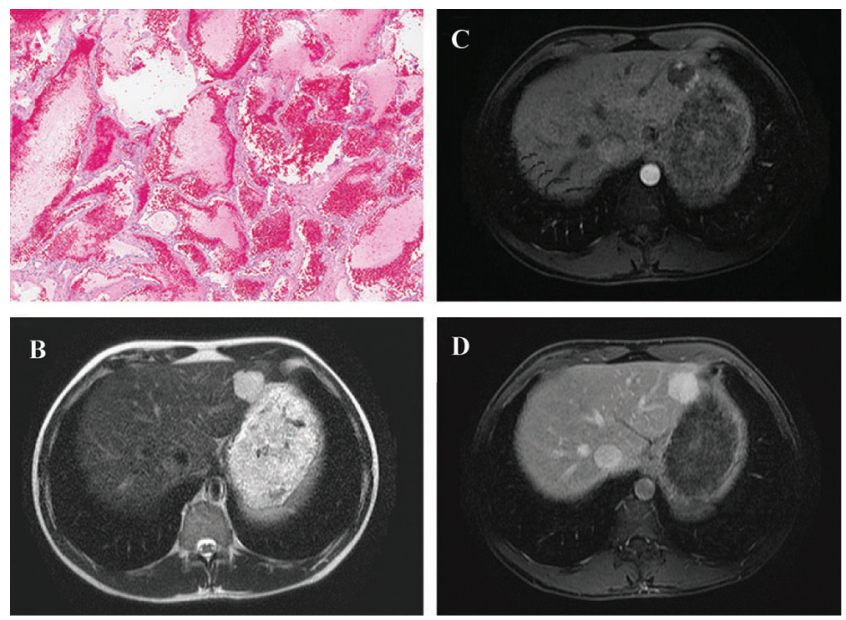

Fig. 4. Hepatic hemangioma. A, Medium magnification showing vascular channels lined by bland and attenuated endothelial cells $[H \& E, \times 100] ; B, T 2$ weighted MRI image showing hyperintense lesion in the left lobe; $C$, MRI arterial phase showing hypointense well-circumscribed lesion with minimal peripheral arterial enhancement; D, MRI portal venous phase showing avidly enhancing well circumscribed lobulated lesion, which has "filled in" on more delayed phase imaging.
Management of hemangiomas consists typically of observation. Treatment of giant hemangiomas - larger than $4-5 \mathrm{~cm}$ - is indicated if they cause abdominal symptoms, complications, or when the diagnosis is uncertain. ${ }^{70,71}$ Hemangiomas rarely rupture but are associated with high mortality in 36-39\% of affected patients. Another uncommon complication is disseminated intravascular coagulation (Kasabach-Merritt syndrome). ${ }^{70}$ Management is usually surgical with enucleation. A recent case series of 20 patients showed that transcatheter arterial embolization was safe and effective in reducing the size and relieving the symptoms over a 6 month follow-up period. ${ }^{72}$

$\mathrm{FNH}$ is the second most common benign solid liver tumor present in approximately $0.3-3 \%$ of the general population. It has a clear female predominance of $10: 1$ and is typically diagnosed between 20-50 years of age. There is no clear evidence linking oral contraceptive (OC) use with $\mathrm{FNH}^{73}$ The tumors are well-differentiated and unencapsulated, consisting of hepatocellular nodules and stromal tissue (Fig. 5). It usually is detected incidentally. On US, FNH usually appears hypoechoic with a hyperechoic central scar. Doppler can demonstrate a central artery with a star pattern. IV contrast can improve ultrasonographic yield and show arterial enhancement with portovenous isoechnogenicity. ${ }^{74-76}$ Nevertheless, CT scan with IV contrast should be performed and would likely show homogeneous enhancement in the arterial phase with a hypodense central scar. ${ }^{77} \mathrm{CT}$ findings are summarized in Table 3.

MRI is particularly useful in the diagnosis of $\mathrm{FNH}$. With gadolinium, the pattern is similar to that found on CT, with rapid arterial enhancement and isointensity during the portal venous and equilibrium images. If a central scar is present, it would appear hyperintense on T2-weighted images and hypointense on T1-weighted images. ${ }^{78}$ These are summarized and compared to other tumors in Table 2. The other main differential diagnosis is HCC (discussed earlier), metastases to the liver, and hepatocellular adenomas. To help further differentiate FNH from HCA, MRI with hepatospecific contrast agents, such as gadoxetate (Primovist in Europe, Eovist in the United States), can be utilized. The concept relies on the histological difference between FNH and HCA. While FNH has a structure similar to normal liver parenchyma, including bile ducts, adenomas, and malignant lesions that lack a biliary system. Eovist is taken up by hepatocytes and excreted with bile. Thus, iso- or hyperintensity on the hepatobiliary phase is $84 \%$ sensitive and $99 \%$ specific to $\mathrm{FNH}^{73,79}$

The vast majority of patients with FNH can be managed conservatively. Elective surgery is indicated if the lesions are symptomatic, malignancy cannot be ruled out, or tumor growth is $>3-5 \mathrm{~cm} /$ year. $^{73}$

HCAs are usually solitary and unencapsulated tumors with central necrosis or hemorrhage, varying in size from $<1 \mathrm{~cm}$ to more than $20 \mathrm{~cm}$ (Fig. 6A). They are mostly located in the right liver lobe (Fig. 6B-6D). The incidence of HCA increased in women after the marketing of $\mathrm{OC}$, and the risk of developing HCA was shown to be 25 times higher in women treated with OC than not. Some evidence indicates that the tumor can regress after discontinuation of OC. Pregnancy, use of anabolic steroids, and obesity are also risk factors for the development of HCA. ${ }^{73}$ HCAs are classified into four different molecular subtypes. Inflammatory HCA is the most common variant. Immunohistochemistry may be helpful in subtyping the adenomas, although the immunohistochemical staining pattern is variable, 

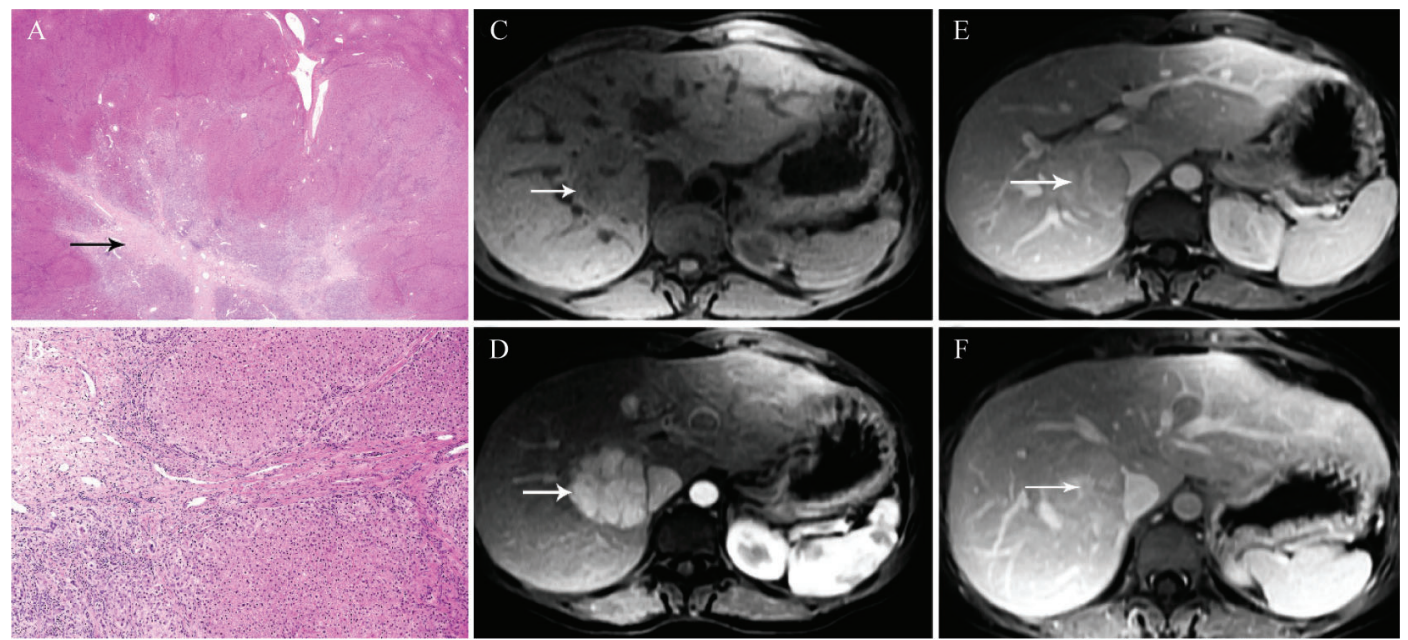

Fig. 5. Pathology and radiology of focal nodular hyperplasia (FNH). A, Scanning view of FNH demonstrating central stellate shape scar (black arrow) [H\&E, $\times 6.6]$; $\mathrm{B}$, FNH showing broad bands of fibrous septa with dystrophic vessels. There is florid bile ductular proliferation along the fibrous septa [H\&E, $\times 100]$; MRI of FNH showing $C$, hypointense lesion on precontrast image; $D$, rapid arterial enhancement; $E$, rapid washout to near background on portal venous; $F$, equilibrium phase with delayed enhancement of central scar.

making the utility in biopsies controversial. ${ }^{80} \mathrm{MRI}$ and $\mathrm{CT}$ findings in HCA are summarized in Table 2 and 3, respectively. ${ }^{73}$

There are no established surveillance programs for patients with HCA. US and periodic measurement of AFP can be considered. Indications for liver resection include tumor size $>5 \mathrm{~cm}$, HCA with activating mutations of the $\beta$-catenin gene, male gender, or patients who are unable to discontinue estrogen therapy. It is recommended that women with tumor size $>5 \mathrm{~cm}$ undergo resection prior to a planned pregnancy. ${ }^{73}$

\section{Liver metastases}

Hepatic metastases are up to 40 times more common than primary liver tumors. The most common sites of primary malignancies that metastasize to the liver are gastrointestinal tract cancers (colorectal cancer, pancreatic cancer, gastric cancer, esophageal cancer, etc.), breast cancer, lung cancer, genitourinary cancers, and melanoma (Fig. 7). The CT appearance of liver metastases is summarized in Table 3. Typically on US, metastatic lesions appear rounded, well-defined, and with a positive mass effect and distortion of adjacent vessels. ${ }^{81}$ MRI characteristics are more variable, but the lesions are frequently hypointense on T1-weighted images, hyperintense on T2-weighted images, and do not retain Eovist on the hepatobiliary phase. ${ }^{82,83}$

\section{Biliary tract malignancies}

Malignancies of the biliary tract are the second most common hepatobiliary cancer after HCC. In order of decreasing incidence, they comprise gallbladder carcinoma, CCA, and carcinoma of the ampulla of Vater.

\section{CCA}

CCAs are malignant tumors that arise from the ductal epithelium of the biliary tree. It is a relatively uncommon tumor with incidence rates ranging from 0.8 to 2 per 100,000 in the Western world, thus making up less than $3 \%$ of all gastrointestinal cancers. ${ }^{84,85}$ Its peak incidence rate is in the seventh decade, with a slight male predilection. ${ }^{86}$ Risk factors for CCA follow a distinct geographic pattern. For example, primary

Table 3. Summary of typical CT scan findings in hepatobiliary tumors

\begin{tabular}{llll}
\hline & Unenhanced & Arterial phase & Portal/venous or delayed phase \\
\hline HCC & $\begin{array}{l}\text { Variable to hypoattenuating } \\
\text { Generally hypoattenuating } \\
\text { with possible central scar }\end{array}$ & $\begin{array}{l}\text { Early enhancement } \\
\text { Hyperattenuating. Central scar } \\
\text { hypoattenuating }\end{array}$ & $\begin{array}{l}\text { Washout } \\
\text { Hypoattenuating. Central scar: } \\
\text { hypoattenuating on portovenous but } \\
\text { hyperattenuating on delayed phase }\end{array}$ \\
CCA & Hypo or isoattenuating & Rapid peripheral enhancement & $\begin{array}{l}\text { Central enhancement and peripheral } \\
\text { iso/hypoattenuation }\end{array}$ \\
FNH & Hypo or isodense & Early homogenous enhancement & $\begin{array}{l}\text { Isoattenuating in portal/venous and } \\
\text { delayed phases. Central scar: } \\
\text { can enhance in delayed phase }\end{array}$ \\
HCA & vith hypodense central scar and & pseudocapsule & Homogenous and isoattenuating \\
Metastases & Hypoattenuating & Rapid enhancement & Hypoattenuating with peripheral enhancement
\end{tabular}

CCA, cholangiocarcinoma; FLC, fibrolamellar hepatocellular carcinoma; FNH, focal nodular hyperplasia; HCA, hepatocellular adenoma; HCC, hepatocellular carcinoma; MRI, magnetic resonance imaging. 
Kabbach G. et al: Hepatobiliary tumors

Table 4. Typical imaging appearance of hepatic hemangiomas

\begin{tabular}{lllll}
\hline & Tumor size & Ultrasound & Unenhanced CT & T2-weighted MRI \\
\hline Cavernous & $<3 \mathrm{~cm}$ & Homogenous and hyperechoic & Similar to blood vessels & Hyperintense (similar to CSF) \\
Capillary & $<1 \mathrm{~cm}$ & Homogenous and hypoechoic & Hypodense & Hyperintense \\
Sclerosing & $\sim 3.7 \mathrm{~cm}$ & Heterogeneous and hyperechoic & Hypoattenuation & $\begin{array}{l}\text { Heterogeneous with peripheral } \\
\text { hyperintensity and a zone of } \\
\text { central sclerosis }\end{array}$ \\
\hline
\end{tabular}

CSF, cerebrospinal fluid; CT, computed tomography; MRI, magnetic resonance imaging.

sclerosing cholangitis is the most common predisposing factor in the West, while liver flukes (Opisthorchis viverrini and Clonorchis sinensis) and hepatolithiasis are significantly more common in the East. ${ }^{85}$ Other risk factors include bile duct cysts, viral hepatitis, and exposure to thorotrast. ${ }^{86}$ Fig. 3B shows typical histological appearance of CCA, which is adenocarcinoma originating from biliary epithelium. ${ }^{87}$ CCAs are subdivided into three groups based on their anatomic location: intrahepatic, perihilar, and distal. ${ }^{88}$ Such distinction is made as it dictates the appropriate surgical treatment. ${ }^{89}$ Perihilar CCA comprises almost $50 \%$ of all CCAs, followed by distal CCA $(40 \%)$, and intrahepatic CCA $(10 \%) .{ }^{90}$ The diagnosis is usually made in the advanced stage of the disease due to its
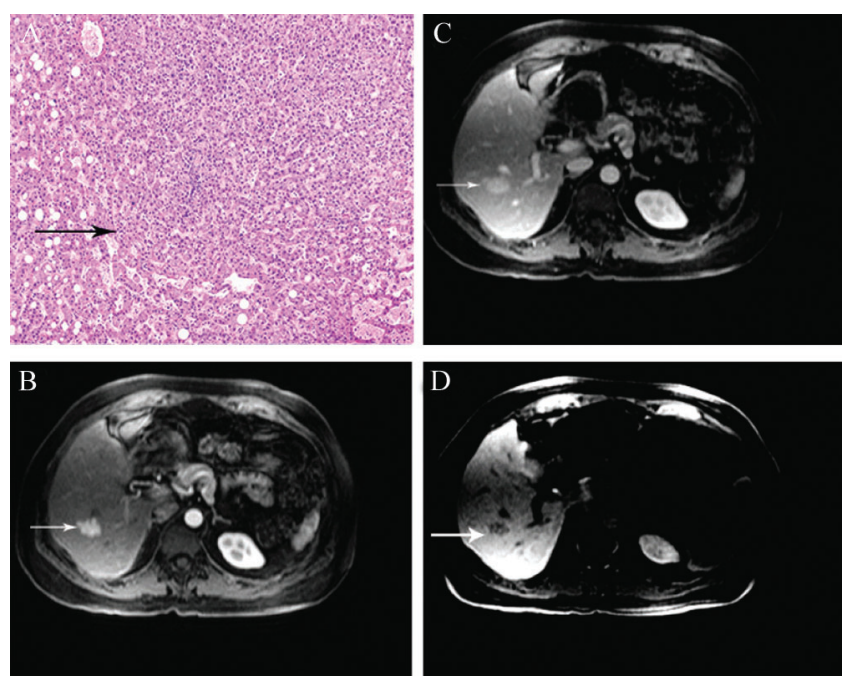

Fig. 6. Pathology and radiology of hepatocellular adenoma (HCA). A, HCA showing scattered arteries unaccompanied by portal veins or bile ducts (unpaired arteries) [H\&E, $\times 100]$; MRI images showing $B$, arterial enhancement; C, some washout on portal venous phase; $D$, hypointensity to liver on hepatobiliary phase.
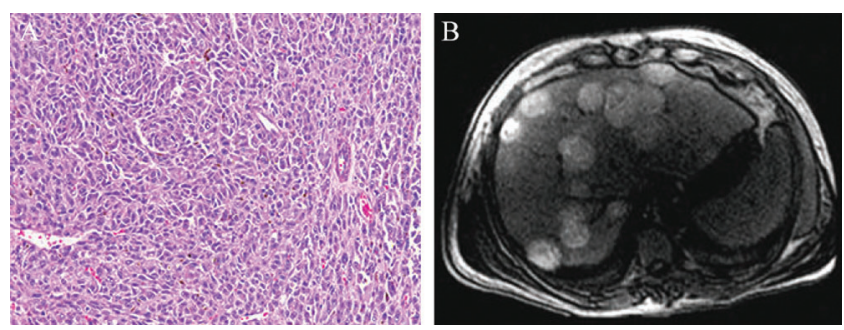

Fig. 7. Metastatic melanoma. A, Pathology slide showing frequent pigments admixed within the tumor and prominent cherry-red nucleoli [H\&E, ×200]; B, T1-weighted MRI showing multiple hyperintense lesions consistent with melanin or hemorrhage. slow growth and lack of specific symptomatology. This translates into a dismal prognosis, with 5 year survival rates less than $5 \% .{ }^{91}$

\section{Intrahepatic CCA}

Intrahepatic CCAs are the second most common intrahepatic primary malignancies after HCC. These include all malignant tumors that arise from biliary epithelium distal to second order bile ducts. ${ }^{92}$ Morphologically, they usually appear as an exophytic intrahepatic mass, although they can also be infiltrating and spreading along the bile ducts. ${ }^{92}$ Intrahepatic CCA usually present with nonspecific symptoms, including abdominal pain, weight loss, and night sweats.

Intrahepatic CCA has variable homogeneity and echogenicity on sonography. ${ }^{93}$ US is not adequate to differentiate it from HCC, even if contrast is used, as intrahepatic CCA may also show washout. ${ }^{94}$ On MRI, intrahepatic CCA is typically hypo- to isointense on T1-weighted images and variably hyperintense on T2-weighted images. With gadolinium, CCA shows enhancement at the periphery early on, followed by progressive, prolonged, and delayed central enhancement (Table 2). ${ }^{92}$ Fig. 8 shows typical MRI appearance of CCA and biliary cystadenoma. Typical CT findings are summarized in Table 3. Positron emission tomography (PET) scan is usually not used as a sole imaging modality due to its inability to differentiate benign from malignant lesions. However, it is
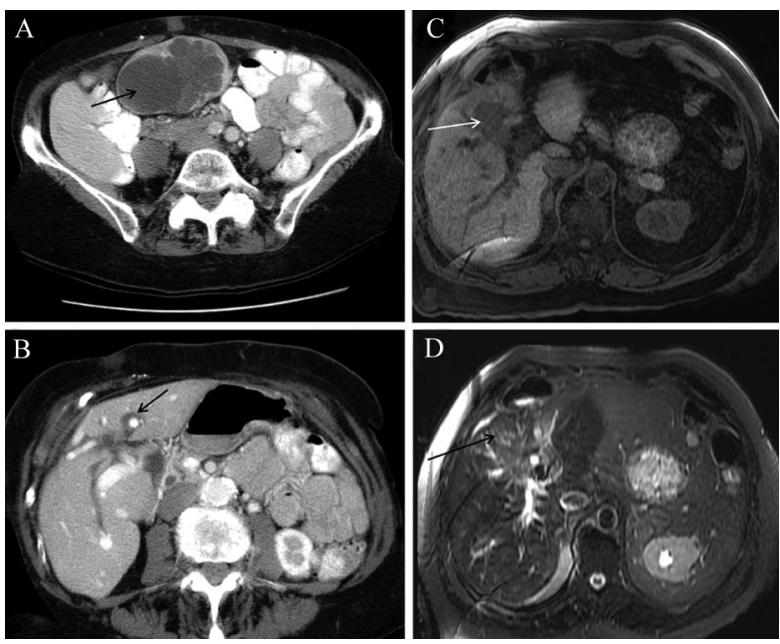

Fig. 8. Radiologic imaging of biliary cystadenoma (A, B), and cholangiocarcinoma (C, D). CT scan showing (A) a heterogenous, complex cystic mass with evidence for (B) biliary dilatation in left hepatic lobe representing biliary cystadenoma. Cholangiocarcinoma appearing as (C) a hypointense mass on T1-weighted MRI and as (D) a hyperintense ill-defined mass on T2-weighted MRI. 
used as a complement to CT or MRI to detect occult distant metastasis. ${ }^{95}$ Laboratory testing can be used as an adjunct to imaging to establish the diagnosis. Unlike HCC, AFP is usually normal or slightly elevated in intrahepatic CCA. CA 19-9 is increased, being more specific in the subset of patients with PSC. ${ }^{92}$ In fact, CA $19-9$ levels above $129 \mathrm{U} / \mathrm{mL}$ is more than $98 \%$ specific for CCA in the setting of PSC. ${ }^{92}$

Intrahepatic CCA has a high rate of recurrence, approaching $70 \%$ in a 5 year period. Surgical resection is performed if the tumor is deemed resectable, and there is no evidence of distant metastasis. Systemic chemotherapy, consisting of gemcitabine and cisplatin, is the standard of treatment for inoperable or metastatic intrahepatic CCA. ${ }^{96}$ Enrollment in an ongoing clinical trial is always a favored option, if available. Palliative treatment options with radiofrequency ablation, chemoembolization, and radioembolization have also been used for locoregional control. ${ }^{92}$

\section{Perihilar CCA}

Perihilar CCAs include all malignant tumors that arise from biliary epithelium anywhere between the second order bile ducts down to the common bile duct at the cystic duct origin. Macroscopically, they are usually periductal infiltrating/ sclerosing type, unlike intrahepatic CCA that present as mass-like type. The tumor grows along the bile duct and forms concentric layers that eventually lead to a stricture with complete obliteration of the duct. Hence, the most common presenting symptom is jaundice, occurring in more than $90 \%$ of patients. Other nonspecific symptoms include nausea, weight loss, and abdominal discomfort.

Imaging is critical in staging of the tumor as well as ruling out other diagnoses, such as choledocholithiasis and external compression of the duct by lymph node. Ultrasonography is regularly performed as an initial test in patients with jaundice. It is useful to rule out benign causes of biliary strictures, but it is not the best modality to rule in/out extrahepatic CCA as the sensitivity and specificity range in the high $80 \%$ s. ${ }^{22}$ Conventional CT scan has a specificity reaching $92 \%$, with high accuracy in detecting vascular involvement and assessing resectability. ${ }^{97,98}$ However, CT scan tends to underestimate the extent of proximal tumors and have a low sensitivity for detection of regional lymphadenopathy. ${ }^{99}$ CT cholangiography is superior to conventional CT as well as US in diagnosing perihilar CCA. Nevertheless, MRCP remains the imaging modality of choice for evaluating extrahepatic CCAs, as it allows for accurate biliary tree mapping. ${ }^{92}$ ERCP and percutaneous transhepatic cholangiography have an added advantage of obtaining tissue biopsy. Brush cytology of biliary strictures can be obtained. Fluorescence in situ hybridization (FISH) polysomy is highly specific, but not very sensitive, in the diagnosis of CCA in patients PSC. ${ }^{100}$ Triple modality testing utilizing brush cytology, forcep biopsy, and FISH showed an improved pooled sensitivity of $82 \%$. ${ }^{101}$

Endoscopic US-guided FNA is useful in assessing the extent of periductal disease and lymphadenopathy. It has a greater sensitivity in detecting distal tumors compared to ERCP. However, its role in evaluating proximal bile duct tumors is uncertain. ${ }^{92}$ Single-operator cholangioscopy (SpyGlass; Direct Visualization System; Boston Scientific, Natick, MA, USA) has shown good results in distinguishing malignant from benign indeterminate biliary strictures, with $100 \%$ positive predictive value and $96 \%$ negative predictive value. ${ }^{102}$ Sensitivity is cited to be between $88-100 \% .{ }^{103,104}$
Accurate evaluation of the extent of tumor is needed to determine resectability. Surgery is the standard treatment modality for localized, resectable tumor. The 5 year survival postresection is between $25-40 \% .{ }^{105}$ Chemotherapy and radiotherapy have not shown any benefit in perihilar CCA, and enrollment in clinical trials is recommended. Biliary drainage is often performed for symptomatic relief in unresectable or metastatic tumors. ${ }^{106}$

\section{Distal CCA}

Perihilar CCAs include all malignant tumors that arise from biliary epithelium anywhere in the common bile duct between (and not including) the cystic duct origin and the ampulla of Vater. Patients usually present with painless jaundice and cholangitis. Diagnosis by imaging modalities is similar to that of perhilar CCA. Treatment considerations are also the same as perihilar CCA, except that the surgery involves a pancreaticoduodenectomy due to the proximity of the tumor to these structures. The 5 year overall survival postresection is $27 \% .^{90}$

\section{Gallbladder carcinoma}

Gallbladder carcinoma is the most common malignancy of the biliary tract, and it is the fifth most common gastrointestinal malignancy. ${ }^{107}$ It includes carcinoma arising from the gallbladder and its cystic duct. Histologically, gallbladder carcinoma usually develops from gastric metaplasia and dysplasia, where $90 \%$ of these cases are initially identified as adenocarcinoma. ${ }^{108}$ As in CCAs, nonspecific late symptomatology and anatomic proximity to other organs leads to late diagnosis and poor prognosis. Survival rates are similar to CAAs, with $5 \%$ of patients surviving at 5 years. ${ }^{109}$ There seems to be a geographic variation in incidence of gallbladder cancer that correlates with the prevalence of its risk factors. Cholelithiasis and chronic Salmonella infections, both being strong predisposing factors to gallbladder cancer, have a high prevalence in South America and Asian countries, which translates into a high incidence of gallbladder carcinoma. ${ }^{110}$ Other known risk factors include porcelain gallbladder, gallbladder polyps, chronic cholecystitis, primary sclerosing cholangitis, congenital biliary cysts, and abnormal pancreatobiliary duct junction, all of which cause chronic inflammation. ${ }^{111}$

Gallbladder cancer clinically presents with symptoms similar to benign diseases of the gallbladder, such as right upper quadrant pain, jaundice, nausea, and vomiting. ${ }^{107}$ Hence, gallbladder tumors are diagnosed late, sometimes incidentally after cholecystectomy for presumed cholecystitis. Only $10 \%$ of tumors are resectable at the time of diagnosis. ${ }^{112}$ Many modalities can be employed to diagnose and stage gallbladder cancer. Ultrasonography is usually the first test done to evaluate the gallbladder in a patient presenting with right upper quadrant pain. Although it can detect large tumors, early lesions are often missed. Endoscopic US has the advantage of being more sensitive in detecting gallbladder tumors and allows for sampling of bile for cytologic analysis and staging of the tumor. ${ }^{92}$ Gallbladder carcinoma is usually hypodense on nonenhanced CT, and wall-thickening is typically asymmetric as opposed to cholecystitis, where the wall thickening tends to be symmetric. CT with contrast shows enhancement that persists in the venous and delayed phases, while HCC typically shows washout in these phases. ${ }^{92} \mathrm{CT}$ is often employed in the staging as well as the 
assessment of resectability. MR may also be useful when combined with angiography to detect vascular and biliary invasion, which could impact resectability. ${ }^{107}$ PET scan is currently not part of the work-up in gallbladder cancer, but data on its use in detecting occult distant metastasis is emerging. ${ }^{92}$

Staging of the tumor is crucial in dictating the appropriate treatment modalities. Surgery is the mainstay of treatment in resectable tumors, ranging from simple cholecystectomy to cholecystectomy with extensive radical resection. ${ }^{107}$ In nonresectable and metastatic disease, chemotherapy with gemcitabine and cisplatin or chemoradiation can prolong survival. ${ }^{107}$ Biliary drainage is performed for symptomatic relief. $^{92}$

\section{Carcinoma of the ampulla of Vater}

Carcinoma of the ampulla of Vater, or ampullary carcinoma, is a very rare tumor with an incidence of 5 per 1 million. ${ }^{113}$ Familial adenomatous polyposis is recognized as an important risk factor. ${ }^{114}$ It tends to have a better prognosis than the other biliary carcinomas due to its early presentation with biliary obstruction and jaundice. Since the ampulla of Vater is at the junction of the duodenal papilla and the bifurcation of the pancreaticobiliary ducts, primary ampullary carcinomas can be classified into intestinal type and pancreaticobiliary type. The former type is more common and has a better prognosis.

Imaging is important in distinguishing ampullary carcinoma from other biliary carcinomas and pancreatic cancer. EUS is the most specific imaging used for local staging of the tumor, as it accurately depicts depth of tumor invasion and invasion of nearby structures. ${ }^{92} \mathrm{ERCP}$ is preferred in patients with jaundice secondary to malignant bile duct obstruction. ${ }^{92}$ MRCP can be used to visualize the pancreaticobiliary tree in patients who cannot tolerate ERCP. CT is inferior to EUS and ERCP in detecting small ampullary tumors and in determining extent of local invasion. ${ }^{115}$ It is used, however, to assess lymphadenopathy and distant metastasis.

Standard treatment is pancreaticoduodenectomy in resectable tumors, with the goal of achieving negative margins. A simple ampullectomy can be considered in small, welldifferentiated, noninvasive tumors. ${ }^{116}$ Systemic chemotherapy or chemoradiation can be used in the adjuvant setting as well as in advanced disease, but data on survival benefit is scarce.

\section{Rare biliary tumors}

There is a myriad of other tumors that may arise in the biliary system that are worth mentioning. Adenomas are benign neoplasms of glandular epithelium that are usually discovered incidentally. The intestinal-type adenoma has a low risk of progression to carcinoma, as opposed to the completely benign pyloric gland adenoma. Bile duct adenoma (also termed biliary hamartoma) is shown in Fig. 9. Biliary papillomatosis represents a disease of multiple adenomas of the bile ducts and are usually difficult to treat surgically due to their multicentricity and high recurrence rates. Granular cell tumors are benign tumors with Schwannian differentiation that arise in the common bile duct. Unlike biliary papillomatosis, granular cell tumors are not at risk of malignant transformation and rarely recur. Rhabdomyosarcoma is a neoplasm that is most frequently described in the biliary tree of children, although it is occasionally seen in the
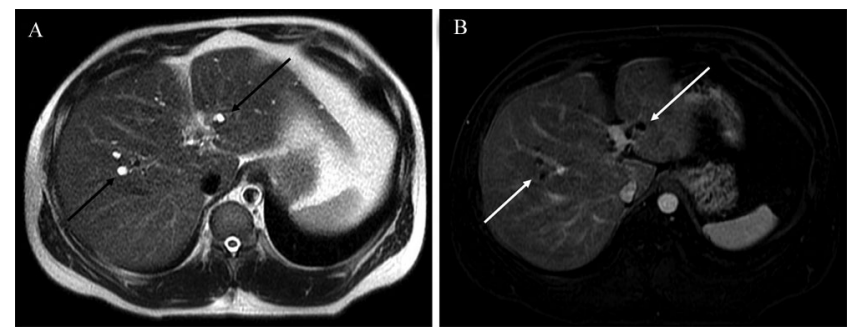

Fig. 9. Biliary hamartomas. A, Hyperintense foci along the biliary tree on T2-weighted images; B, Well-defined hypointense lesions on T1-weighted image postcontrast.

gallbladder of elderly patients. Prognosis is usually poor, with treatment commonly involving a multimodal approach using surgery, chemotherapy, and radiation. Neuroendocrine carcinomas and carcinoid tumors rarely occur in the biliary system, and they usually behave similarly to their counterpart in other organs. ${ }^{117}$ The epidemiology, diagnosis, and treatment of these rare biliary tumors are beyond the scope of this article.

\section{Conclusions}

Hepatobiliary malignancies, most notably HCC, are common fatal cancers that continue to be on the rise and to pose a diagnostic and therapeutic challenge. No single biomarker is yet available for the diagnosis of hepatobiliary cancers, and international guidelines differ markedly in their utilization of imaging modalities for surveillance and diagnosis. Despite extensive clinical trials, sorafenib remains the only approved agent for the treatment of advanced liver cancer, with new agents constantly being tested in ongoing first line and second line clinical trials.

\section{Conflict of interest}

None

\section{Author contributions}

Drafting and revising the manuscript (GK, HA), providing radiology images (GB, $\mathrm{MS})$, providing pathology images and editing the manuscript $(\mathrm{HJL})$, conceiving this work, giving critical comments and revising the manuscript (MT).

\section{References}

[1] Torre LA, Bray F, Siegel RL, Ferlay J, Lortet-Tieulent J, Jemal A. Global cancer statistics, 2012. CA Cancer J Clin 2015;65:87-108. doi: 10.3322/caac. 21262.

[2] Kudo M. Emerging strategies for the management of hepatocellular carcinoma. Dig Dis 2014;32:655-657. doi: 10.1159/000367981.

[3] Ferlay J, Shin HR, Bray F, Forman D, Mathers C, Parkin DM. Estimates of worldwide burden of cancer in 2008: GLOBOCAN 2008. Int J Cancer 2010; 127:2893-2917. doi: 10.1002/ijc.25516.

[4] El-Serag HB, Kanwal F. Epidemiology of hepatocellular carcinoma in the United States: where are we? Where do we go? Hepatology 2014;60: 1767-1775. doi: 10.1002/hep.27222.

[5] Bosetti C, Turati F, La Vecchia C. Hepatocellular carcinoma epidemiology. Best Pract Res Clin Gastroenterol 2014;28:753-770. doi: 10.1016/j.bpg. 2014.08.007.

[6] El-Serag HB, Kanwal F. Obesity and hepatocellular carcinoma: hype and reality. Hepatology 2014;60:779-781. doi: 10.1002/hep.27172. 
[7] Forner A, Llovet JM, Bruix J. Hepatocellular carcinoma. Lancet 2012;379: 1245-1255. doi: 10.1016/S0140-6736(11)61347-0.

[8] Buendia MA, Neuveut C. Hepatocellular Carcinoma. Cold Spring Harb Perspect Med 2015;5:a021444. doi: 10.1101/cshperspect.a021444.

[9] Beasley RP, Hwang LY, Lin CC, Chien CS. Hepatocellular carcinoma and hepatitis B virus. A prospective study of 22707 men in Taiwan. Lancet 1981;2:1129-1133. doi: 10.1016/S0140-6736(81)90585-7.

[10] Kim MN, Han KH, Ahn SH. Prevention of Hepatocellular Carcinoma: Beyond Hepatitis B Vaccination. Semin Oncol 2015;42:316-328. doi: 10.1053/j. seminoncol.2014.12.018.

[11] El-Serag HB. Hepatocellular carcinoma. N Engl J Med 2011;365:1118-1127. doi: 10.1056/NEJMra1001683.

[12] Nault JC. Pathogenesis of hepatocellular carcinoma according to aetiology. Best Pract Res Clin Gastroenterol 2014;28:937-947. doi: 10.1016/j.bpg. 2014.08.006.

[13] Jee SH, Ohrr H, Sull JW, Samet JM. Cigarette smoking, alcohol drinking, hepatitis B, and risk for hepatocellular carcinoma in Korea. J Natl Cancer Inst 2004;96:1851-1856. doi: 10.1093/jnci/djh334.

[14] Herrigel DJ, Moss RA. Diabetes mellitus as a novel risk factor for gastrointestinal malignancies. Postgrad Med 2014;126:106-118. doi: 10.3810/ pgm.2014.10.2825.

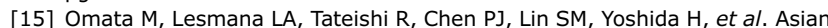
Pacific Association for the Study of the Liver consensus recommendations on hepatocellular carcinoma. Hepatol Int 2010;4:439-474. doi: 10.1007/ s12072-010-9165-7.

[16] European Association For The Study Of The Liver, European Organisation For Research And Treatment Of Cancer. EASL-EORTC clinical practice guidelines: management of hepatocellular carcinoma. J Hepatol 2012;56: 908-943. doi: 10.1016/j.jhep.2011.12.001.

[17] Bruix J, Sherman M, American Association for the Study of Liver Diseases. Management of hepatocellular carcinoma: an update. Hepatology $2011 ; 53$ : 1020-1022. doi: 10.1002/hep.24199.

[18] Zhang BH, Yang BH, Tang ZY. Randomized controlled trial of screening for hepatocellular carcinoma. J Cancer Res Clin Oncol 2004;130:417-422.

[19] McMahon BJ, Bulkow L, Harpster A, Snowball M, Lanier A, Sacco F, et al. Screening for hepatocellular carcinoma in Alaska natives infected with chronic hepatitis B: a 16-year population-based study. Hepatology 2000; 32:842-846. doi: 10.1053/jhep.2000.17914.

[20] Singal AG, Conjeevaram HS, Volk ML, Fu S, Fontana RJ, Askari F, et al. Effectiveness of hepatocellular carcinoma surveillance in patients with cirrhosis. Cancer Epidemiol Biomarkers Prev 2012;21:793-799. doi: 10. 1158/1055-9965.EPI-11-1005.

[21] Schutte K, Schulz C, Link A, Malfertheiner P. Current biomarkers for hepatocellular carcinoma: Surveillance, diagnosis and prediction of prognosis. World J Hepatol 2015;7:139-149. doi: 10.4254/wjh.v7.i2.139.

[22] Song $P$, Feng $X$, Inagaki $Y$, Song $T$, Zhang $K$, Wang $Z$, et al. Clinical utility of simultaneous measurement of alpha-fetoprotein and des-gamma-carboxy prothrombin for diagnosis of patients with hepatocellular carcinoma in China: A multi-center case-controlled study of 1,153 subjects. Biosci Trends 2014;8:266-273. doi: 10.5582/bst.2014.01116.

[23] Johnson PJ, Pirrie SJ, Cox TF, Berhane S, Teng M, Palmer D, et al. The detection of hepatocellular carcinoma using a prospectively developed and validated model based on serological biomarkers. Cancer Epidemiol Biomarkers Prev 2014;23:144-153. doi: 10.1158/1055-9965.EPI-13-0870.

[24] Li LM, Hu ZB, Zhou ZX, Chen X, Liu FY, Zhang JF, et al. Serum microRNA profiles serve as novel biomarkers for HBV infection and diagnosis of HBVpositive hepatocarcinoma. Cancer Res 2010;70:9798-9807. doi: 10.1158/ 0008-5472.CAN-10-1001.

[25] Xu J, Wu C, Che X, Wang L, Yu D, Zhang T, et al. Circulating microRNAs, miR21 , miR-122, and miR-223, in patients with hepatocellular carcinoma or chronic hepatitis. Mol Carcinog 2011;50:136-142. doi: 10.1002/mc. 20712.

[26] Kokudo N, Hasegawa K, Akahane M, Igaki H, Izumi N, Ichida T, et al. Evidence-based Clinical Practice Guidelines for Hepatocellular Carcinoma: The Japan Society of Hepatology 2013 update (3rd JSH-HCC Guidelines). Hepatol Res 2015;45. doi: 10.1111/hepr.12464.

[27] Ronot M, Vilgrain V. Hepatocellular carcinoma: diagnostic criteria by imaging techniques. Best Pract Res Clin Gastroenterol 2014;28:795-812. doi: $10.1016 /$ j.bpg.2014.08.005.

[28] Zheng SG, Xu HX, Liu LN. Management of hepatocellular carcinoma: The role of contrast-enhanced ultrasound. World J Radiol 2014;6:7-14. doi: 10. 4329/wjr.v6.i1.7.

[29] Shah S, Shukla A, Paunipagar B. Radiological features of hepatocellular carcinoma. J Clin Exp Hepatol 2014;4:S63-S66. doi: 10.1016/j.jceh. 2014.06.009.

[30] Wee A. Fine-needle aspiration biopsy of hepatocellular carcinoma and related hepatocellular nodular lesions in cirrhosis: controversies, challenges, and expectations. Patholog Res Int 2011;2011:587936. doi: 10. $4061 / 2011 / 587936$.
[31] Llovet JM, Bru C, Bruix J. Prognosis of hepatocellular carcinoma: the BCLC staging classification. Semin Liver Dis 1999;19:329-338. doi: 10.1055/ s-2007-1007122.

[32] Leung TW, Tang AM, Zee B, Lau WY, Lai PB, Leung KL, et al. Construction of the Chinese University Prognostic Index for hepatocellular carcinoma and comparison with the TNM staging system, the Okuda staging system, and the Cancer of the Liver Italian Program staging system: a study based on 926 patients. Cancer 2002;94:1760-1769. doi: 10.1002/cncr.10384.

[33] Seong J, Shim SJ, Lee IJ, Han KH, Chon CY, Ahn SH. Evaluation of the prognostic value of Okuda, Cancer of the Liver Italian Program, and Japan Integrated Staging systems for hepatocellular carcinoma patients undergoing radiotherapy. Int J Radiat Oncol Biol Phys 2007;67:1037-1042. doi: 10.1016/j.ijrobp.2006.10.035.

[34] Tabrizian P, Roayaie S, Schwartz ME. Current management of hepatocellular carcinoma. World J Gastroenterol 2014;20:10223-10237. doi: 10.3748/ wjg.v20.i30.10223.

[35] Llovet JM, Fuster J, Bruix J. Intention-to-treat analysis of surgical treatment for early hepatocellular carcinoma: resection versus transplantation. Hepatology 1999;30:1434-1440. doi: 10.1002/hep.510300629.

[36] Shindoh J, CW DT, Vauthey JN. Portal vein embolization for hepatocellular carcinoma. Liver cancer 2012;1:159-167. doi: 10.1159/000343829.

[37] Pang TC, Lam VW. Surgical management of hepatocellular carcinoma. World J Hepatol 2015;7:245-252. doi: 10.4254/wjh.v7.i2.245.

[38] Imamura H, Matsuyama Y, Tanaka E, Ohkubo T, Hasegawa K, Miyagawa S, et al. Risk factors contributing to early and late phase intrahepatic recurrence of hepatocellular carcinoma after hepatectomy. J Hepatol 2003;38: 200-207. doi: 10.1016/S0168-8278(02)00360-4.

[39] Kalyan A, Nimeiri H, Kulik L. Systemic Therapy of Hepatocellular Carcinoma: Current and Promising. Clin Liver Dis 2015;19:421-432. doi: 10.1016/j. cld.2015.01.009.

[40] Mazzaferro V, Regalia E, Doci R, Andreola S, Pulvirenti A, Bozzetti F, et al. Liver transplantation for the treatment of small hepatocellular carcinomas in patients with cirrhosis. N Engl J Med 1996;334:693-699. doi: 10.1056/ NEJM199603143341104.

[41] Yao FY, Ferrell L, Bass NM, Watson JJ, Bacchetti P, Venook A, et al. Liver transplantation for hepatocellular carcinoma: expansion of the tumor size limits does not adversely impact survival. Hepatology 2001;33:13941403. doi: 10.1053/jhep.2001.24563.

[42] Qi HL, Zhuang BJ, Li CS, Liu QY. Peri-operative use of sorafenib in liver transplantation: a time-to-event meta-analysis. World J Gastroenterol 2015;21:1636-1640. doi: 10.3748/wjg.v21.i5.1636.

[43] Kan X, Jing Y, Wan QY, Pan JC, Han M, Yang Y, et al. Sorafenib combined with percutaneous radiofrequency ablation for the treatment of medium-sized hepatocellular carcinoma. Eur Rev Med Pharmacol Sci 2015;19:247-255.

[44] Feng X, Xu R, Du X, Dou K, Qin X, Xu J, et al. Combination therapy with sorafenib and radiofrequency ablation for BCLC Stage 0-B1 hepatocellular carcinoma: a multicenter retrospective cohort study. Am J Gastroenterol 2014;109:1891-1899. doi: 10.1038/ajg.2014.343.

[45] Bester L, Meteling B, Pocock N, Saxena A, Chua TC, Morris DL. Radioembolisation with Yttrium-90 microspheres: an effective treatment modality for unresectable liver metastases. J Med Imaging Radiat Oncol 2013;57: 72-80. doi: 10.1111/j.1754-9485.2012.02459.x.

[46] Erhardt A, Kolligs F, Dollinger M, Schott E, Wege H, Bitzer M, et al. TACE plus sorafenib for the treatment of hepatocellular carcinoma: results of the multicenter, phase II SOCRATES trial. Cancer Chemother Pharmacol 2014;74: 947-954. doi: 10.1007/s00280-014-2568-8.

[47] Lencioni R. Chemoembolization in patients with hepatocellular carcinoma. Liver Cancer 2012;1:41-50. doi: 10.1159/000339019.

[48] Kudo M, Han G, Finn RS, Poon RT, Blanc JF, Yan L, et al. Brivanib as adjuvant therapy to transarterial chemoembolization in patients with hepatocellular carcinoma: A randomized phase III trial. Hepatology 2014;60:1697-1707. doi: $10.1002 /$ hep. 27290 .

[49] Chuma M, Terashita K, Sakamoto N. New molecularly targeted therapies against advanced hepatocellular carcinoma: From molecular pathogenesis to clinical trials and future directions. Hepatol Res 2014. doi: $10.1111 / \mathrm{hepr}$. 12459.

[50] Cheng AL, Kang YK, Chen Z, Tsao CJ, Qin S, Kim JS, et al. Efficacy and safety of sorafenib in patients in the Asia-Pacific region with advanced hepatocellular carcinoma: a phase III randomised, double-blind, placebo-controlled trial. Lancet Oncol 2009;10:25-34. doi: 10.1016/S1470-2045(08)70285-7.

[51] Llovet JM, Ricci S, Mazzaferro V, Hilgard P, Gane E, Blanc JF, et al. Sorafenib in advanced hepatocellular carcinoma. N Engl J Med 2008;359:378-390. doi: $10.1056 /$ NEJMoa0708857.

[52] Lencioni R, Kudo M, Ye SL, Bronowicki JP, Chen XP, Dagher L, et al. GIDEON (Global Investigation of therapeutic decisions in hepatocellular carcinoma and Of its treatment with sorafeNib): second interim analysis. Int J Clin Pract 2014;68:609-617. doi: 10.1111/ijcp.12352.

[53] Zhu AX, Rosmorduc O, Evans TR, Ross PJ, Santoro A, Carrilho FJ, et al. SEARCH: A Phase III, Randomized, Double-Blind, Placebo-Controlled Trial 
of Sorafenib Plus Erlotinib in Patients With Advanced Hepatocellular Carcinoma. J Clin Oncol 2015;33:559-566. doi: 10.1200/JCO.2013.53.7746.

[54] Cainap C, Qin S, Huang WT, Chung IJ, Pan H, Cheng Y, et al. Linifanib versus Sorafenib in patients with advanced hepatocellular carcinoma: results of a randomized phase III trial. J Clin Oncol 2015;33:172-179. doi: 10.1200/ JCO.2013.54.3298.

[55] Zhu AX, Kudo M, Assenat E, Cattan S, Kang YK, Lim HY, et al. Effect of everolimus on survival in advanced hepatocellular carcinoma after failure of sorafenib: the EVOLVE-1 randomized clinical trial. JAMA 2014;312:57-67. doi: 10.1001/jama.2014.7189.

[56] Oi XS, Guo XZ, Han GH, Li HY, Chen J. MET inhibitors for treatment of advanced hepatocellular carcinoma: A review. World J Gastroenterol 2015;21:5445-5453. doi: 10.3748/wjg.v21.i18.5445.

[57] Mavros MN, Mayo SC, Hyder O, Pawlik TM. A systematic review: treatment and prognosis of patients with fibrolamellar hepatocellular carcinoma. J Am Coll Surg 2012;215:820-830. doi: 10.1016/j.jamcollsurg.2012.08.001.

[58] El-Serag HB, Davila JA. Is fibrolamellar carcinoma different from hepatocellular carcinoma? A US population-based study. Hepatology 2004;39: 798-803. doi: 10.1002/hep.20096.

[59] Ward SC, Waxman S. Fibrolamellar carcinoma: a review with focus on genetics and comparison to other malignant primary liver tumors. Semin Liver Dis 2011;31:61-70. doi: 10.1055/s-0031-1272835.

[60] Ganeshan D, Szklaruk J, Kundra V, Kaseb A, Rashid A, Elsayes KM. Imaging features of fibrolamellar hepatocellular carcinoma. AJR Am J Roentgenol 2014;202:544-552. doi: 10.2214/AJR.13.11117.

[61] Graham RP, Jin L, Knutson DL, Kloft-Nelson SM, Greipp PT, Waldburger N, et al. DNAJB1-PRKACA is specific for fibrolamellar carcinoma. Mod Pathol 2015;28:822-829. doi: 10.1038/modpathol.2015.4.

[62] Mayo SC, Mavros MN, Nathan H, Cosgrove D, Herman JM, Kamel I, et al. Treatment and prognosis of patients with fibrolamellar hepatocellular carcinoma: a national perspective. J Am Coll Surg 2014;218:196-205. doi: 10. 1016/j.jamcollsurg.2013.10.011.

[63] Choi KH, Moon WS. Epithelioid hemangioendothelioma of the liver. Clin Mol Hepatol 2013;19:315-319. doi: 10.3350/cmh.2013.19.3.315.

[64] Pedrassa BC, da Rocha EL, Kierszenbaum ML, Bormann RL, Torres LR, D'Ippolito G. Uncommon hepatic tumors: iconographic essay - Part 1. Radiol Bras 2014;47:310-316. doi: 10.1590/0100-3984.2013.1760.

[65] Sangro B, Inarrairaegui M, Fernandez-Ros N. Malignant epithelioid hemangioendothelioma of the liver successfully treated with Sorafenib. Rare Tumors 2012; 4:e34. doi: 10.4081/rt.2012.e34.

[66] Remiszewski P, Szczerba E, Kalinowski P, Gierej B, Dudek K, Grodzicki M, et al. Epithelioid hemangioendothelioma of the liver as a rare indication for liver transplantation. World J Gastroenterol 2014;20:11333-11339. doi: 10.3748/wjg.v20.i32.11333.

[67] Lupinacci RM, Rocha Mde S, Herman P. Hepatic epithelioid hemangioendothelioma: an unusual lesion of the liver. Clin Gastroenterol Hepatol 2012; 10:e15-e16. doi: 10.1016/j.cgh.2011.10.010.

[68] Taseva A, Tasev V, Bulanov D, Dimitrov K, Popov V, Zivkov E, et al. Diagnosis of liver hemangioma. Khirurgiia (Sofiia) 2013:8-13.

[69] Doyle D], Khalili K, Guindi M, Atri M. Imaging features of sclerosed hemangioma. AJR Am J Roentgenol 2007;189:67-72.

[70] Toro A, Mahfouz AE, Ardiri A, Malaguarnera M, Malaguarnera G, Loria F, et al. What is changing in indications and treatment of hepatic hemangiomas. A review. Ann Hepatol 2014;13:327-339.

[71] Tuxun T, Apaer S, Zhou CM, Zhang JH, Zhao JM, Tai QW, et al. Surgery vs. observation for liver hemangioma: a systematic review and meta-analysis. Hepatogastroenterology 2014;61:2377-2382.

[72] Firouznia K, Ghanaati H, Alavian SM, Nassiri Toosi M, Ebrahimi Daryani N, Jalali $\mathrm{AH}$, et al. Management of liver hemangioma using trans-catheter arterial embolization. Hepat Mon 2014;14:e25788. doi: 10.5812/hepatmon. 25788.

[73] Cristiano A, Dietrich A, Spina JC, Ardiles V, de Santibanes E. Focal nodular hyperplasia and hepatic adenoma: current diagnosis and management. Updates Surg 2014;66:9-21. doi: 10.1007/s13304-013-0222-3.

[74] Nat L, Poanta LI. Focal nodular hyperplasia (FNH). Rom J Intern Med 2014; 52:45-49.

[75] Li W, Wang W, Liu GJ, Chen LD, Wang Z, Huang Y, et al. Differentiation of Atypical Hepatocellular Carcinoma from Focal Nodular Hyperplasia: Diagnostic Performance of Contrast-enhanced US and Microflow Imaging. Radiology 2015:140911. doi: 10.1148/radiol.14140911.

[76] Kong WT, Wang WP, Huang BJ, Ding H, Mao F, Si Q. Contrast-Enhanced Ultrasound in Combination with Color Doppler Ultrasound Can Improve the Diagnostic Performance of Focal Nodular Hyperplasia and Hepatocellular Adenoma. Ultrasound Med Biol 2015;41:944-951. doi: 10.1016/j.ultrasmedbio.2014. 11.012.

[77] Carlson SK, Johnson CD, Bender CE, Welch TJ. CT of focal nodular hyperplasia of the liver. AJR Am J Roentgenol 2000;174:705-712.

[78] Khanna M, Ramanathan S, Fasih N, Schieda N, Virmani V, McInnes MD. Current updates on the molecular genetics and magnetic resonance imaging of focal nodular hyperplasia and hepatocellular adenoma. Insights Imaging 2015;6:347-362. doi: 10.1007/s13244-015-0399-8.

[79] Yoon JH, Kim JY. Atypical Findings of Focal Nodular Hyperplasia with Gadoxetic Acid (Gd-EOB-DTPA)-Enhanced Magnetic Resonance Imaging. Iran J Radiol 2014;11:e9269. doi: 10.5812/iranjradiol.9269.

[80] Dhingra S, Fiel MI. Update on the new classification of hepatic adenomas: clinical, molecular, and pathologic characteristics. Arch Pathol Lab Med 2014;138:1090-1097. doi: 10.5858/arpa.2013-0183-RA.

[81] Wernecke K, Vassallo P, Bick U, Diederich S, Peters PE. The distinction between benign and malignant liver tumors on sonography: value of a hypoechoic halo. AJR Am J Roentgenol 1992;159:1005-1009.

[82] Namasivayam S, Martin DR, Saini S. Imaging of liver metastases: MRI. Cancer Imaging 2007;7:2-9. doi: 10.1102/1470-7330.2007.0002

[83] Danet IM, Semelka RC, Leonardou P, Braga L, Vaidean G, Woosley JT, et al. Spectrum of MRI appearances of untreated metastases of the liver. AJR Am J Roentgenol 2003;181:809-817.

[84] Rajagopalan V, Daines WP, Grossbard ML, Kozuch P. Gallbladder and biliary tract carcinoma: A comprehensive update, Part 1. Oncology (Williston Park) 2004;18:889-896.

[85] Augustine MM, Fong Y. Epidemiology and risk factors of biliary tract and primary liver tumors. Surg Oncol Clin N Am 2014;23:171-188. doi: 10. 1016/j.soc.2013.10.001.

[86] Sainani NI, Catalano OA, Holalkere NS, Zhu AX, Hahn PF, Sahani DV. Cholangiocarcinoma: current and novel imaging techniques. Radiographics 2008;28:1263-1287. doi: 10.1148/rg.285075183.

[87] Khan SA, Davidson BR, Goldin R, Pereira SP, Rosenberg WM, Taylor-Robinson $\mathrm{SD}$, et al. Guidelines for the diagnosis and treatment of cholangiocarcinoma: consensus document. Gut 2002;51:VI1-VI9. doi: 10.1136/gut.51.suppl_6. vi1.

[88] Razumilava N, Gores GJ. Classification, diagnosis, and management of cholangiocarcinoma. Clin Gastroenterol Hepatol 2013;11:13-21.e11; quiz e13-e14. doi: 10.1016/j.cgh.2012.09.009.

[89] Blechacz B, Komuta M, Roskams T, Gores GJ. Clinical diagnosis and staging of cholangiocarcinoma. Nature reviews. Nat Rev Gastroenterol Hepatol 2011;8:512-522. doi: 10.1038/nrgastro.2011.131.

[90] DeOliveira ML, Cunningham SC, Cameron JL, Kamangar F, Winter JM, Lillemoe KD, et al. Cholangiocarcinoma: thirty-one-year experience with 564 patients at a single institution. Ann Surg 2007;245:755-762. doi: 10. 1097/2F01.sla.0000251366.62632.d3.

[91] Mosconi S, Beretta GD, Labianca R, Zampino MG, Gatta G, Heinemann V. Cholangiocarcinoma. Crit Rev Oncol Hematol 2009;69:259-270. doi: 10. 1016/j.critrevonc.2008.09.008.

[92] Hennedige TP, Neo WT, Venkatesh SK. Imaging of malignancies of the biliary tract- an update. Cancer Imaging $2014 ; 14: 14$. doi: 10.1186/1470-733014-14.

[93] Ros PR, Buck JL, Goodman ZD, Ros AM, Olmsted WW. Intrahepatic cholangiocarcinoma: radiologic-pathologic correlation. Radiology 1988;167: 689-693. doi: 10.1148/radiology.167.3.2834769.

[94] Vilana R, Forner A, Bianchi L, García-Criado A, Rimola J, de Lope CR, et al. Intrahepatic peripheral cholangiocarcinoma in cirrhosis patients may display a vascular pattern similar to hepatocellular carcinoma on contrastenhanced ultrasound. Hepatology 2010;51:2020-2029. doi: 10.1002/hep. 23600.

[95] Anderson CD, Rice MH, Pinson CW, Chapman WC, Chari RS, Delbeke D. Fluorodeoxyglucose PET imaging in the evaluation of gallbladder carcinoma and cholangiocarcinoma. J Gastrointest Surg 2004;8:90-97.

[96] Valle J, Wasan H, Palmer DH, Cunningham D, Anthoney A, Maraveyas A et $a l$. Cisplatin plus gemcitabine versus gemcitabine for biliary tract cancer. N Engl J Med 2010;362:1273-1281. doi: 10.1056/NEJMoa0908721.

[97] Kim TK, Choi BI, Han JK, Jang HJ, Cho SG, Han MC. Peripheral cholangiocarcinoma of the liver: two-phase spiral CT findings. Radiology 1997;204: 539-543. doi: 10.1148/radiology.204.2.9240550.

[98] Aloia TA, Charnsangavej C, Faria S, Ribero D, Abdalla EK, Vauthey JN, et al. High-resolution computed tomography accurately predicts resectability in hilar cholangiocarcinoma. Am J Surg 2007;193:702-706. doi: 10.1016/ j.amjsurg.2006.10.024.

[99] Vilgrain V. Staging cholangiocarcinoma by imaging studies. HPB (Oxford) 2008;10:106-109. doi: 10.1080/13651820801992617.

[100] Navaneethan U, Njei B, Venkatesh PG, Vargo J], Parsi MA. Fluorescence in situ hybridization for diagnosis of cholangiocarcinoma in primary sclerosing cholangitis: a systematic review and meta-analysis. Gastrointest Endosc 2014;79:943-950.e943. doi: 10.1016/j.gie.2013.11.001.

[101] Nanda A, Brown JM, Berger SH, Lewis MM, Barr Fritcher EG, Gores GJ, et al. Triple modality testing by endoscopic retrograde cholangiopancreatography for the diagnosis of cholangiocarcinoma. Therap Adv Gastroenterol 2015;8: 56-65. doi: 10.1177/1756283X14564674.

[102] Tieu AH, Kumbhari V, Jakhete N, Onyimba F, Patel Y, Shin EJ, et al. Diagnostic and therapeutic utility of SpyGlass peroral cholangioscopy in intraductal biliary disease: Single-center, retrospective, cohort study. Dig Endosc 2014;27:479-485. doi: 10.1111/den.12405. 
[103] Woo YS, Lee JK, Oh SH, Kim MJ, Jung JG, Lee KH, et al. Role of SpyGlass peroral cholangioscopy in the evaluation of indeterminate biliary lesions. Dig Dis Sci 2014;59:2565-2570. doi: 10.1007/s10620-014-3171-x.

[104] Manta R, Frazzoni M, Conigliaro R, Maccio L, Melotti G, Dabizzi E, et al. SpyGlass single-operator peroral cholangioscopy in the evaluation of indeterminate biliary lesions: a single-center, prospective, cohort study. Surg Endosc 2013;27:1569-1572. doi: 10.1007/s00464-012-2628-2.

[105] Aljiffry M, Walsh MJ, Molinari M. Advances in diagnosis, treatment and palliation of cholangiocarcinoma: 1990-2009. World J Gastroenterol 2009;15: 4240-4262. doi: 10.3748/2Fwjg.15.4240.

[106] Vanderveen KA, Hussain HK. Magnetic Resonance Imaging of cholangiocarcinoma. Cancer Imaging 2004;4:104-115. doi: 10.1102/1470-7330. 2004.0018.

[107] Rakic M, Patrlj L, Kopljar M, Kliček R, Kolovrat M, Loncar B, et al. Gallbladder cancer. Hepatobiliary Surg Nutr 2014;3:221-226. doi: 10.3978/j.issn. 2304-3881.2014.09.03.

[108] Mukhopadhyay S, Landas SK. Putative precursors of gallbladder dysplasia: a review of 400 routinely resected specimens. Arch Pathol Lab Med 2005; 129:386-390.

[109] Levy AD, Murakata LA, Rohrmann CA Jr. Gallbladder carcinoma: radiologicpathologic correlation. Radiographics 2001;21:295-314; questionnaire, 549-555. doi: 10.1148/radiographics.21.2.g01mr16295.

[110] Wistuba II, Gazdar AF. Gallbladder cancer: lessons from a rare tumour. Nat Rev Cancer 2004;4:695-706. doi: 10.1038/nrc1429.
[111] Hundal R, Shaffer EA. Gallbladder cancer: epidemiology and outcome. Clin Epidemiol 2014;6:99-109. doi: 10.2147/CLEP.S37357.

[112] Sheth S, Bedford A, Chopra S. Primary gallbladder cancer: recognition of risk factors and the role of prophylactic cholecystectomy. Am J Gastroenterol 2000;95:1402-1410. doi: 10.1111/j.1572-0241.2000.02070.x.

[113] Albores-Saavedra J, Schwartz AM, Batich K, Henson DE. Cancers of the ampulla of vater: demographics, morphology, and survival based on 5,625 cases from the SEER program. J Surg Oncol 2009;100:598-605. doi: $10.1002 /$ jso. 21374.

[114] Mantas D, Charalampoudis P, Nikiteas N. FAP related periampullary adenocarcinoma. International journal of surgery case reports. 2013;4:684-686. doi: $10.1016 /$ j.ijscr.2013.05.006.

[115] Skordilis P, Mouzas IA, Dimoulios PD, Alexandrakis G, Moschandrea J, Kouroumalis $E$. Is endosonography an effective method for detection and local staging of the ampullary carcinoma? A prospective study. BMC Surg 2002; 2:1. doi: 10.1186/1471-2482-2-1.

[116] Woo SM, Ryu JK, Lee SH, Lee WJ, Hwang JH, Yoo JW, et al. Feasibility of endoscopic papillectomy in early stage ampulla of Vater cancer. J Gastroenterol Hepatol 2009;24:120-124. doi: 10.1111/j.1440-1746. 2008.05578.x.

[117] Lamps LW. Diagnostic Pathology: Hepatobiliary and Pancreatic. 1st edition. Altona, Manitoba, Canada: Amirsys, 2011. 